\title{
STUDIES ON THE PIGMENTS OF MARINE ANIMALS -IX. PIGMENTS OF THE SEA-SLUG APLYSIA KURODAI-
}

$\operatorname{AUTHOR}(S)$ :

Nishibori, Kokichi

\section{CITATION:}

Nishibori, Kokichi. STUDIES ON THE PIGMENTS OF MARINE ANIMALS -IX. PIGMENTS OF THE SEA-SLUG APLYSIA KURODAI-. PUBLICATIONS OF THE SETO MARINE BIOLOGICAL LABORATORY 1960, 8(2): 327-335

\section{ISSUE DATE:}

1960-12-20

URL:

http://hdl.handle.net/2433/174646

RIGHT: 


\title{
STUDIES ON THE PIGMENTS OF MARINE ANIMALS
}

IX. PIGMENTS OF THE SEA-SLUG APL YSIA KURODAI

\author{
KOKICHI NISHIBORI
}

Notre Dame Seishin University, Okayama

With Plate XXXVI, 6 Tables and 5 Text-figures

The purple ink secretion secreted from the ink-gland (gland of Bahatsh) of Aplysia, has been studied by many workers and the name of aplysiopurpurin is given for this pigment.

An intensive study was carried out by Lederer and HUtTrer (1942) on the aplysiopurpurin of Aplysia punctata.

They pointed out that aplysiopurpurin contains two kinds of chromoprotein, one of which is a violet component, and the other, a red component. They found that aplysioviolin, a prosthetic group of the violet chromoprotein and aplysiorhodin, a prosthetic group of the red chromoprotein which resemble mesobilibiolin and mesobilirhodin respectively in their properties. They concluded that aplysioviolin and aplysiorhodin are bilidiene (having two $-\mathrm{CH}=$ and one $-\mathrm{CH}_{2}-$ group in the tetrapyrrol chain).

Three pigments (violet, red, and green) were separated chromatographically from the secretion of Aplysia depilans by Christomanos (1955), who suggests that these three pigments are porphyrin pigment.

The author examined the pigments of purple secretion and of orange coloured ova of Aplysia kurodai and two pigments (blue and red) were separated from the secretion. They are bile pigment, not porphyrin pigment.

The pigment of ova is carotenoid, which was isolated in crystalline form.

\section{Material}

The specimens used were collected at Moheji, Hakodate and carried back to the laboratory within 4 to 6 hours. The purple secretion was obtained from the ink-gland of living specimens. The ova of Aplysia which are found on the rock of sea-shoals, were collected at the same place.

Publ. Seto Mar. Biol. Lab., VIII (2), 1960. (Article 25) 


\section{Experiment and Result}

I. Pigment of secretion

1. General properties of purple secretion. The secretion is a deep purple-blue viscous fluid having a halogen smell. None of the colourless chromogen was detected. The purple secretion was easily soluble in sea-water or water and showed a purple colour which changed to red-purple and red when it was diluted. The pigment was not extracted with petroleum ether, ether and benzene. When acetone and alcohol were added, the colour of the secretion changed from purple to red and a red-orange fluorescence appeared with a white precipitate.

Pigment was precipitated from the water solution of the secretion by the addition of ammonium sulphate. The mother solution was almost colourless (light yellow in colour).

The purple precipitate, thus obtained, was insoluble in petroleum ether, ether and chloroform but soluble in water. The purple pigment is not dialised by cellophane membrane, but passes through the film when methanol or hydrochloric acid are added. These properties indicate that the purple pigment forms chromoprotein.

The purple colour of the secretion is easily decolourized, especially by light. When the secretion is allowed to stand for three or four days in a room, the colour changes from purple to red-purple and finally dark-brown. The same discolouration was found in the purple salting-out precipitate.

2. Variation of absorption spectra effected by light and acid. The absorption curve, exhibiting the maxima at $495,550 \mathrm{~m} \mu$, of the natural purple secrtion is shown in Fig. 1. Reported absorption maxima of the purple secretion are as follows (Table 1).

Table 1. Absorption maxima of the purple secretion of Aplysia.

\begin{tabular}{lll|l}
\hline \multicolumn{2}{c|}{ Absorption maxima $\left(\mathrm{m}_{\mu}\right)$} & \multicolumn{1}{c}{ Worker } \\
\hline 497.5, & 535, & $610^{*}$ & CHRISTOMANOS (1955) \\
491, & 550, & 591 & FoNTAINE and RAFFY (1936)** \\
493, & 545, & 597 & LEDERER and HUTTRER (1942) \\
495, & 550, & 595 & SCHREIBER (1932)** \\
495, & 550 & & The author \\
\hline
\end{tabular}

* measured in chloroform solution.

** after Lederer and HutTrer (1942).

For the purpose of determining the instability of the pigment to light, the change of the absorption curve was measured when the secretion was exposed under the sun-light.

The results, as shown in Table 2 and in Fig. 1 , indicate that the maximum 
Table 2. Absorption maxima of the secretion exposed to the sun. (in water)

\begin{tabular}{|c|c|c|c|c|}
\hline Secretion & Colour of soln. & \multicolumn{3}{|c|}{ Absorp. $\max .(\mathrm{m} \mu)$} \\
\hline $\begin{array}{l}\text { Natural fresh secretion } \\
\text { Expose to the sun for } 5 \mathrm{~min} .^{*} \\
\text { Expose to the sun for } 10 \mathrm{~min} .^{*} \\
\text { Expose to the sun for } 30 \mathrm{~min} \text {. and } \\
\text { allow to stand in the room for one } \\
\text { night* }\end{array}$ & $\begin{array}{l}\text { purple-blue } \\
\text { purple-red } \\
\text { red } \\
\text { dirty brown }\end{array}$ & $\begin{array}{l}- \\
- \\
-, \\
410,\end{array}$ & $\begin{array}{l}495, \\
495, \\
495, \\
510\end{array}$ & $\begin{array}{r}<550 \\
\rightleftharpoons 540 \\
>540 \\
-\end{array}$ \\
\hline
\end{tabular}

* Before the sun-exposure, the secretion was kept in dark for one night.

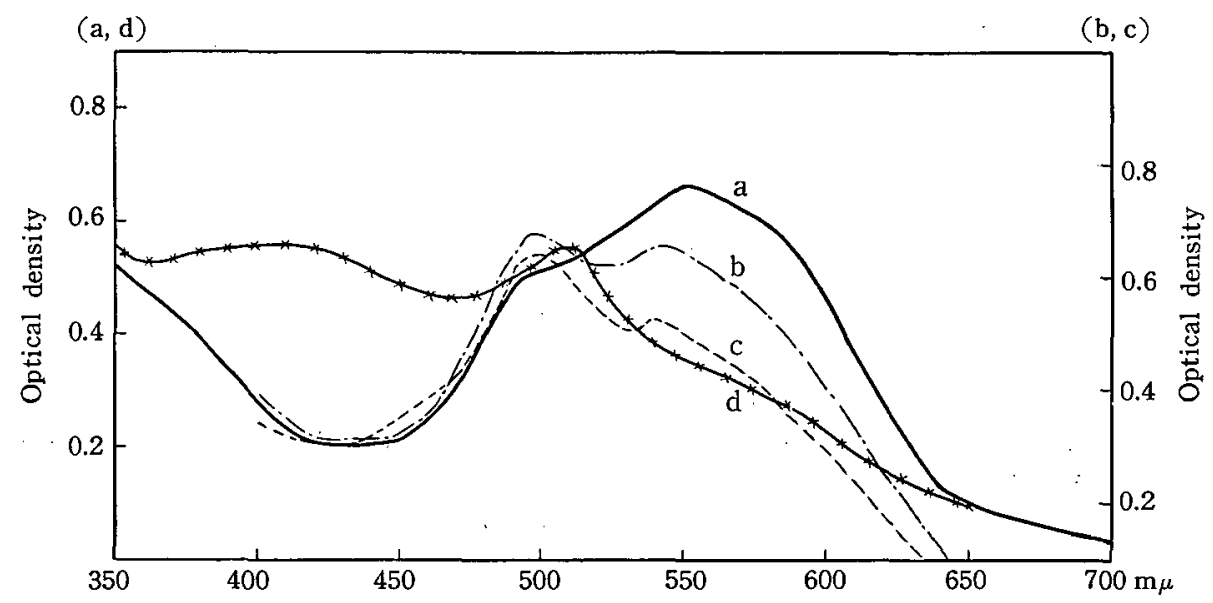

Fig. 1. Absorption spectra of the pigment of purple secretion from Aplysia kurodai. (in water).

a) Natural secretion, b) Expose to the sun for five min., c) Expose to the sun for ten min., d) Expose to the sun for thirty min. and allow to stand in the room for one night.

at $550 \mathrm{~m} \mu$ is displaced toward at $540 \mathrm{~m} \mu$ lessened gradually and a new broad maximum at $410 \mathrm{~m} \mu$ appeared contrarily. The colour of the purple secretion became a dark dirty brown finally.

The colour of the secretion changed from purple to deep blue-purple when acidified with dilute hydrochloric acid, blue colour of which is stable and can be

Table 3. Absorption maxima of the secretion acidified with dilute hydrochloric acid.

\begin{tabular}{l|l|rc}
\hline \multicolumn{1}{c|}{ Pigment of secretion } & \multicolumn{1}{c|}{ Colour of soln. } & Absorp. max. (m $\mu)$ \\
\hline Natural fresh secretion in water & purple-blue & 495,550 \\
Acidified purple secretion with dil. $\mathrm{HCl}$ & deep blue-purple & 495, & 573 \\
$\begin{array}{l}\text { Chloroform extract of acidified sec- } \\
\text { retion }\end{array}$ & deep blue & $\sim 500,560$, & 605 \\
$\begin{array}{l}\text { Acidified secretion after chloroform } \\
\text { extraction }\end{array}$ & red & 493,555 \\
\hline
\end{tabular}




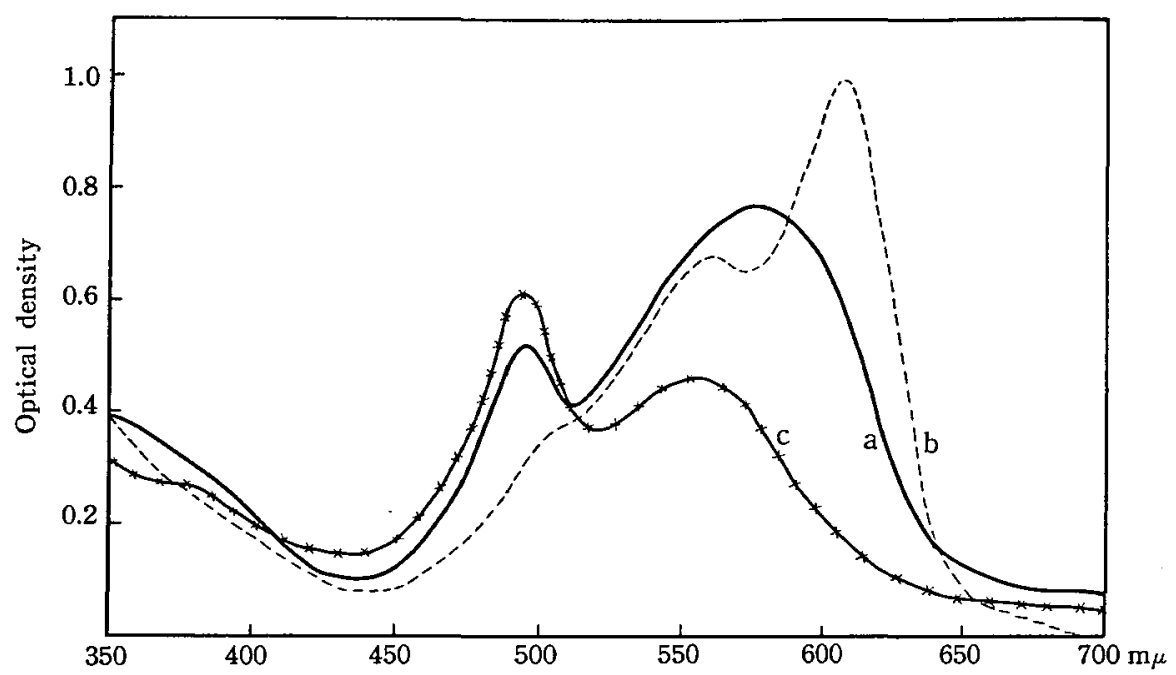

Fig. 2. Absorption spectra of the pigment of purple secretion from Aplysia kurodai.

a) Acidified purple secretion with dilute hydrochloric acid.

b) Chloroform extract from acidified secretion.

c) Acidified secretion after chloroform extraction.

extracted therefrom with chloroform. The absorption maxima and the absorption curves of these, were shown in Table 3 and Fig. 2. These results show that the pigment of secretion can be separated into two fractions from acidified secretion; the blue pigment which was extracted with chloroform and the chloroforminsoluble red pigment remaining in the mother solution.

3. Separation of blue and red pigment. The separation method was shown in Table 4.

Table 4. Separation method of the pigment of purple secretion.

\section{Purple secretion}

Add dil. HCl and extract with chloroform

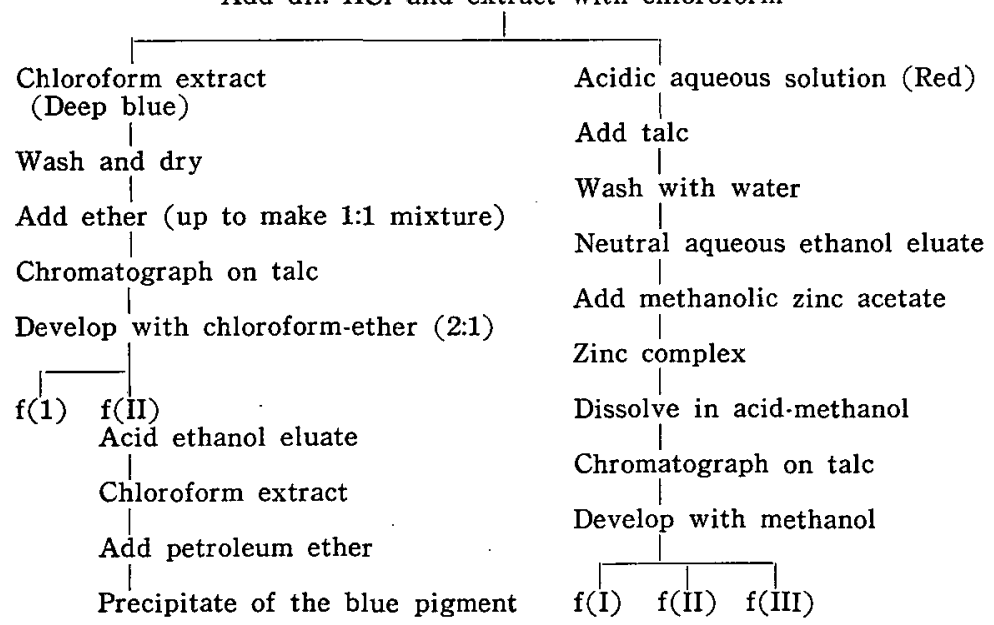


a) Blue pigment. The blue pigment was extracted repeatedly with chloroform from acidified secretion fluid. After washing and drying, the chloroform extract was mixed with the same quantity of ether and was chromatographed upon the column of talc and developed with chloroform-ether (2:1) mixture. Then, the upper dark red-brown zone $f(I)$ and the lower main violet zone $f($ II) were obtained. The pigment was eluted with dilute hydrochloric acid-ethanol from each adsorbed fraction and extracted therefrom with chloroform. The blue pigment of $f(I I)$ in chloroform solution was precipitated as homogeneous hexagonal blue solids by the addition of petroleum ether. The properties of the blue pigment are as follows : absorption maxima, $\sim 505,568,608 \mathrm{~m} \mu$ in acid chloroform, $\sim 505,536, \sim 600 \mathrm{~m} \mu$ in neutral chloroform; zinc-complex in methanol, 510,555 , $600 \mathrm{~m} \mu$ (Table 5, Fig. 3). Solubility, - easily soluble in chloroform, acetone, ethanol, methanol; sparingly soluble in benzene, ether; insoluble in water, petroleum ether. Zinc-urobilin reaction, - the methanolic zinc acetate is added to the methanol solution of the blue pigment $f(I I)$ and an intense deep crimson fluorescence appears and black-violet precipitates (zinc-complex) are obtained by an

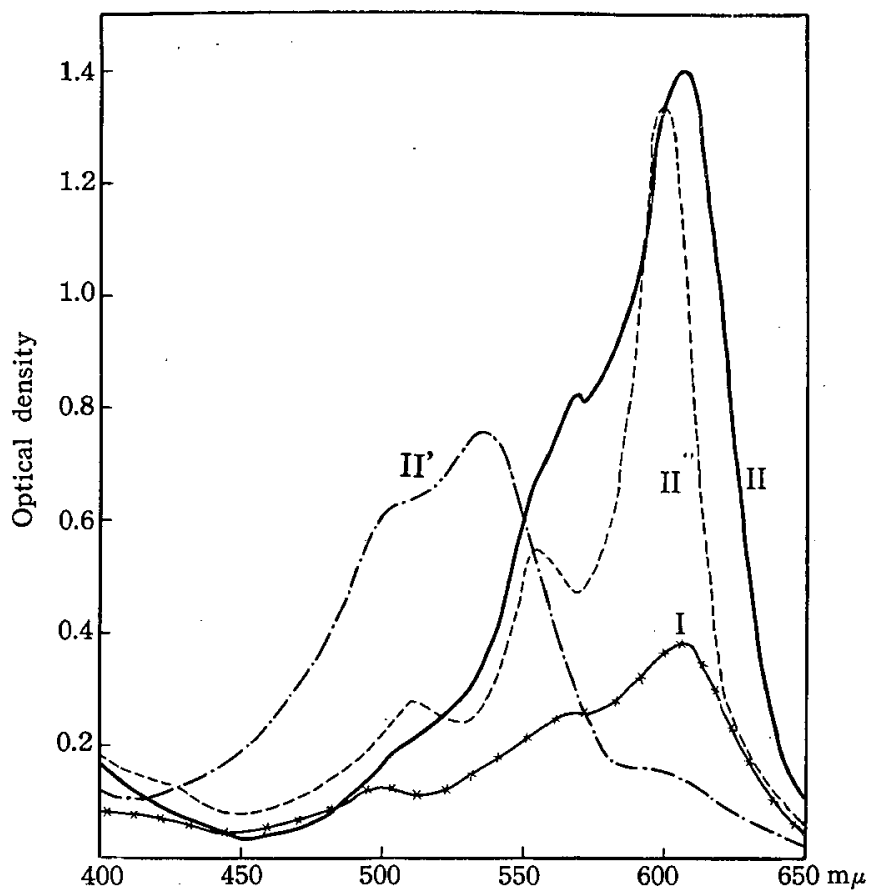

Fig. 3. Absorption spectra of the blue pigment of secretion from Aplysia kurodai.

I) Blue pigment $f(I)$ in acid chloroform.

II) Blue pigment $\mathbf{f}($ II $)$ in acid chloroform.

II') Blue pigment $f(I I)$ in neutral chloroform.

$\left.\mathrm{II}^{\prime \prime}\right)$ Zinc-complex of blue pigment $f(\mathrm{II})$ in methanol. 
Table 5. Absorption maxima of the blue pigment of secretion.

\begin{tabular}{|c|c|c|c|}
\hline Blue pigment & Colour of soln. & \multicolumn{2}{|c|}{ Absorp. $\max .(\mathrm{m} \mu)$} \\
\hline Blue pigment $f(I)$ in acid chloroform & blue & 500,565 , & 605 \\
\hline $\begin{array}{l}\text { Blue pigment } f(I) \text { in neutral chloro. } \\
\text { form }\end{array}$ & light purple-red & 495,538 , & 593 \\
\hline $\begin{array}{l}\text { Zinc complex of blue pigment } f(I) \text { in } \\
\text { methanol }\end{array}$ & blue-purple & 510,555 , & 600,630 \\
\hline Blue pigment $f(I I)$ in acid chloroform & blue & $\sim 505,568$ & 608 \\
\hline $\begin{array}{l}\text { Blue pigment } f(I I) \text { in neutral chloro- } \\
\text { form }\end{array}$ & red & $\sim 505,536$ & $\sim 600$ \\
\hline $\begin{array}{l}\text { Zinc complex of blue pigment } f(I I) \text { in } \\
\text { methanol }\end{array}$ & blue-purple & 510,555 , & 600 \\
\hline
\end{tabular}

addition of a small amount of water. The zinc-complex is reversibly decomposed by acid. The absorption maxima of the zinc-complex was shown above. GMELIN test, - the colour of the chloroform solution of the blue pigment $f($ II) changes as follows when fuming nitric acid is added; purple-red $\rightarrow$ blue $\rightarrow$ purple $\rightarrow$ redpurple $\rightarrow$ pink $\rightarrow$ orange $\rightarrow$ orange-yellow. Ferric chloride and CARR-PRICE reactions are negative.

b) Red pigment. By an addition of talc to the blue pigment-free secretion fluid, the red pigment was adsorbed with talc and precipitated. The red pigment was eluted with neutral methanol-water mixture from the adsorbate after washing with water and then the methanolic zinc acetate was added. The black-violet zinc complexes (absorption maxima, 510,543, 582, $628 \mathrm{~m} \mu$ in neutral ethanol), having a green-brown fluorescence, were precipitated. The red pigment regenerated from the zinc-complex which was dissolved in dilute hydrochloric acid-methanol (absorption maxima, $495,565 \mathrm{~m} \mu$ in acid methanol), was insoluble in chloroform and the GMELIN test on dilute hydrochloric acid solution of the red pigment shows the following colour change: orange, purple, and red purple from the bottom of the test tube.

The red pigment in dilute hydrochloric acid-methanol solution was chromatographed upon the talc and developed with methanol. Three zones were obtained and the colour and the absorption maxima of each zone were summarized in Table 6 and Fig. 4.

Table 6. Absorption maxima of the red pigment of the secretion of $A$. kurodai in acid-methanol.

\begin{tabular}{c|cc}
\hline \multicolumn{1}{c|}{ Red pigment } & Absorp. max. (m $\mu)$ \\
\hline $\mathrm{f}(\mathrm{I})$, the upper main red-purple zone, & 495, & 558 \\
$\mathrm{f}(\mathrm{II})$, the middle purple zone, & 495, & 578 \\
$\mathrm{f}(\mathrm{III})$, the lower light purple zone, & $\sim 495$, & 570 \\
\hline
\end{tabular}




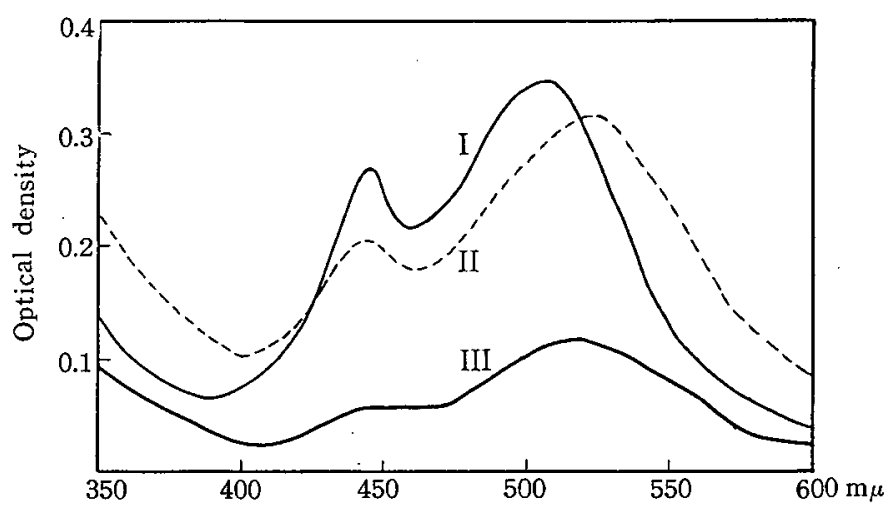

Fig. 4. Absorption spectra of the red pigment of secretion from Aplysia kurodai in acid-methanol.

I) The principal red pigment $f(I)$.

II) Red pigment $\mathbf{f}(\mathrm{II})$.

III) Red pigment f(III).

The principal red pigment is in $f(I)$.

\section{Pigment of ova}

An amount of $90 \mathrm{~g}$ of orange coloured fresh ova of the Aplysia were treated with acetone and the pigment transferred therefrom into the petroleum ether, and then into a small amount of $90 \%$ methanol solution. When the $90 \%$ methanol solution was covered with a layer of petroleum ether and diluted with water, fine crystals, shaping orange-coloured long plate, appeared at the boundary of the two layers. After washing with petroleum ether, the crystals showed the melting point at $175 \sim 178^{\circ}$ (Plate XXXVI, fig. 1). CARRPRICE and conc. $\mathrm{H}_{2} \mathrm{SO}_{4}$ reactions were positive, blue.

The absorption maxima are at $\sim 435,460,488 \mathrm{~m} \mu$ in chloroform (Fig.

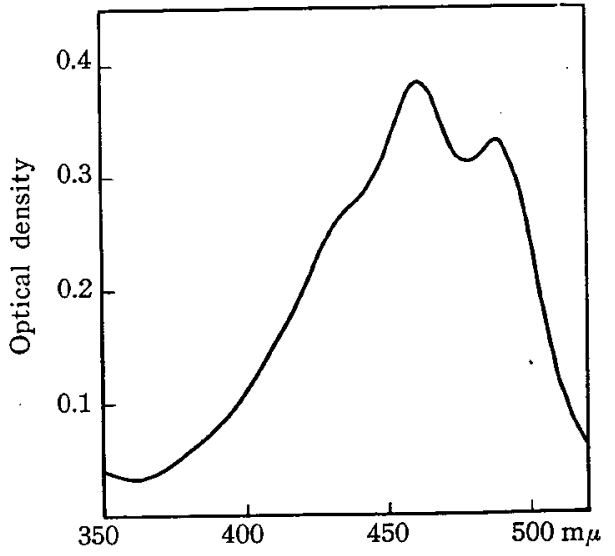

Fig. 5. Absorption spectrum of the carotenoid in the ova of Aplysia kurodai. (in chloroform)

5). It possessed a hypophasic property.

\section{Discussion}

I. Pigment of secretion

The following properties, the GMELIN test, the zinc urobilin reaction, the 
solubility and the absorption spectra show that the blue pigment is a bile pigment, not a porphyrin pigment for lack of the maximum at $400 \mathrm{~m} \mu$.

The series of colour changes found in the GMELIN test of the blue pigment, is similar to those of aplysioviolin, on which LEDERER and HUTTRER (1942) conclude that this colour reaction is typical for bile pigment.

Although the red pigment is different from the blue pigment in insolubility for chloroform, the properties, such as the absorption curve, and the zinc-urobilin reaction, indicate that this red pigment is also a bile pigment.

Сhristomanos (1955), however, has reported the presence of porphyrin pigment in the secretion of Aplysia depilans.

The shape of the absorption curve of the blue pigment of the secretion from Aplysia kurodai, resembles phycocyan (SvedBerg and LEwIs, 1928) which is a blue chromoprotein of red algae. LEDERER and HUTTRER point out that aplysioviolin resembles mesobiliviolin in absorption maxima. Mesobiliviolin is closely related to mesobilicyanin which is the prosthetic group of phycocyan, because both the two bile pigments can be derived chemically from urobilin. It is interesting to note that there is some relation between the pigment of Aplysia secretion and sea algae which are food for Aplysia.

II. Pigment of ova

The ova's pigment is a free xanthophyllic carotenoid which possesses a hypophasic property. Further study was impossible for the lack of the pigment.

\section{Summary}

1. The pigment of the purple secretion and of the orange-coloured ova of Aplysia kurodai was studied.

2. The general properties of the secretion and the effect by light and acid to the pigment of the secretion were examined.

3. The two principal pigments, blue and red, were separated from the secretion. It was noticeable that these two pigments were bile pigment.

4. The pigment of the ova of this sea slug, is a free xanthophyllic carotenoid, which was isolated in crystalline form, and has a hypophasic property.

\section{Acknowledgment}

The author wishes to express his deep gratitude to Professor Y. Nakamura and Professor T. SAITo of Hokkaido University, for their encouragement and guidance. The author is also grateful to Dr. H. Utinomi of Seto Marine Biological Laboratory of Kyoto University who gave the opportunity for publication. 


\section{REFERENCES}

Christomanos, A. 1955. Nature of the pigment of Aplysia depilans. Nature, $175: 310$.

LEDERER, E. et HuTTRER, C. 1942. Quelque observations sur les pigments de la sécrétion des Aplysies (Aplysia punctata). Soc. chim. biol., 24 : 1055-1061.

SvedBerg, N. and LEwis, N. B. 1928. The molecular weights of phycoerythrin and of phycocyan. J. A. C. S., 50:527-536.

\section{EXPLANATION OF PLATE XXXVI}

Fig. 1. Carotenoid in the ova of Aplysia kurodai. 


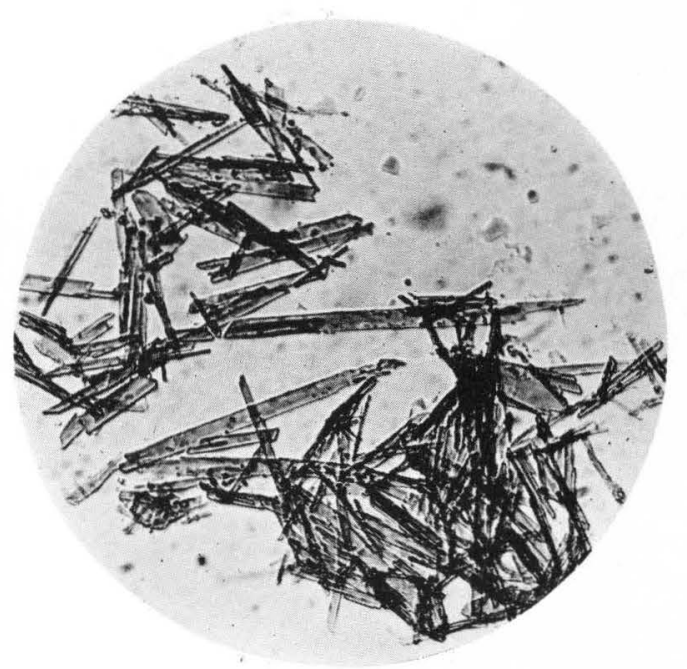

K. Nishibori: Studies on the Pigments of Marine Animals, IX. 